\title{
Editorial \\ Complex Systems Research in K12 Science Education: A Focus on What Works for Whom and under Which Conditions
}

\author{
Susan A. Yoon
}

check for

updates

Citation: Yoon, S.A. Complex Systems Research in K12 Science Education: A Focus on What Works for Whom and under Which

Conditions. Systems 2021, 9, 29. https://doi.org/10.3390/ systems 9020029

Received: 9 April 2021

Accepted: 16 April 2021

Published: 21 April 2021

Publisher's Note: MDPI stays neutral with regard to jurisdictional claims in published maps and institutional affiliations.

Copyright: (c) 2021 by the author Licensee MDPI, Basel, Switzerland. This article is an open access article distributed under the terms and conditions of the Creative Commons Attribution (CC BY) license (https:// creativecommons.org/licenses/by/ $4.0 /)$
Graduate School of Education, University of Pennsylvania, Philadelphia, PA 19104, USA; yoonsa@upenn.edu

From fighting disease to reversing environmental damage, the quest to effectively model our bodies, our social groups and our effects on the planet is a profoundly important one. As explorers, we must seek to replace the indistinct regions on our maps with meaningful topographies, and in so doing, better know ourselves. [1]

Scientists create computational models or simulations in order to understand complex scientific phenomena, explore questions, and increase the rate of innovation and discovery. In K12 education, learning to use, modify, create, and analyze models of scientific systems promotes epistemological understanding of science where students can investigate mechanisms and patterns, and evaluate evidence from their models to construct disciplinary knowledge.

Over the last several decades, education and learning sciences researchers have worked to develop curriculum and instruction programs to support the use of such computational systems models in classrooms. Alongside this research, there have been calls to determine the variables in educational systems that will enable the optimal implementation for successful learning of all students. McKenney [2] writes,

We need research that can help us design for implementation in the here and now. This includes putting the investigation of what works, for whom, under which conditions into a broader perspective to help us ... attend to the highly varied needs of teachers and learners in diverse settings. (p. 2)

In this Special Issue, we aim to illustrate innovative research programs that focus on the implementation of computational systems modeling tools for K12 science teachers and students. Two central goals motivate the articles in this issue. The first is to highlight learning challenges of specific educational populations for which the modeling of scientific systems - through its affordances of interactivity, visualizations, dynamic emergent properties, and access to hidden systems features-can support learning. The second is to identify and investigate the variables of equity and access in educational systems that support or impede participation with modeling resources.

Historically, these two goals have not made it into the mainstream of $\mathrm{K} 12$ science education research on complex systems interventions. Yoon et al. [3] conducted a systematic review of 20 years of published research in this field. Analyses of the 75 peer-reviewed journal articles demonstrated that a majority of studies did not report on or differentiate between populations of learners in terms of demographics and contexts and almost a third of the studies were conducted under laboratory conditions. That study also revealed few efforts to research the ways that teachers could be supported in terms of their own learning of systems and pedagogical knowledge to teach it in their classrooms. The authors recommended more research on the contextual factors that could impact the learning environment and populations including teacher learning.

Furthermore, as we are hopefully moving beyond the height of the COVID-19 crisis, societies need to come to terms with a great deal of misinformation that has been propagated about how the virus spreads, how the spread can be mitigated, and the best 
methods of protection against the disease. This, coupled with the fact that there are still many unknown variables about the efficacy of the vaccines and variant strains of the virus, underscores the importance of becoming literate about system processes such as emergence, feedback loops, random variation, cascading effects, and network structures. Becoming literate about how to read and use scientific models has never before been more important than now.

Fortunately, the modeling tool called StarLogo upon which the research in the four special issue articles is based, has a long-standing history of high quality curricular and instructional interventions that date back to research and development in the 1990s. Yoon [3] discusses this genre of systems modeling as agent-based and built on the dynamic process of emergence where multiple agents with defined characteristics interact at the micro or local level producing patterns of behaviors and states at a macro or global level. An important key feature of the StarLogo platform is its affordance to allow the user to study the code that operates the simulation to determine how each of the agents and their interactions are programmed. Users can then compare the code to the visualization of the system on the screen as it is running in real time. Research using such agent-based modeling tools has shown that the ability to study the code while visualizing the system, in addition to the ability to observe systems processes as they emerge over time, creates far deeper meaning for users than when learning from static images [4,5]. StarLogo also allows users to manipulate system variables to create different initial conditions, modify interactional states and agent characteristics, and adjust how fast or slow or specify the period of time that the simulation runs in order to experiment with the tool.

The four studies selected for this Special Issue serve to illustrate efforts to address the aforementioned dearth of research on complex systems in science education that focuses on what works for whom and under which conditions [6-9]. They also demonstrate the versatility of the modeling tool for learning with diverse populations from elementary students to high school science teachers and with participant demographics that are less often studied in complex systems educational research, i.e., English language learners and underrepresented school districts. The Special Issue concludes with two commentary articles by esteemed scholars in science education and complex systems research. The first, by Okhee Lee, discusses the commonalities between the articles in promoting equity and access of scientific content through the four different research programs that were afforded by the StarLogo modeling tool. The second, by Eric Klopfer, provides a history of the modeling tool itself and its power in terms of promoting domain specific learning of science content and domain general learning of complex systems mechanisms.

Collectively, this set of six papers provides insight into theories and applications that make high quality learning through computational systems modeling accessible for multiple populations and contexts. Our hope is to spur other educational systems researchers to focus on similar goals for K12 science educators and students.

\section{References}

1. National Academies. Keck Futures Initiative: Complex Systems: Task Group Summaries; National Academies Press: Washington, DC, USA, 2009.

2. McKenney, S. How can the learning sciences (better) impact policy and practice? J. Learn. Sci. 2018, 27, 1-7. [CrossRef]

3. Yoon, S.A.; Goh, S.-E.; Park, M. Teaching and learning about complex systems in K-12 science education: A review of empirical studies 1995-2015. Rev. Educ. Res. 2018, 88, 285-325. [CrossRef]

4. Yoon, S.A.; Klopfer, E.; Anderson, E.; Koehler-Yom, J.; Sheldon, J.; Schoenfeld, I.; Goh, S. Designing computer-Supported complex systems curricula for the Next Generation Science Standards in high school science classrooms. Systems 2016, 4, 38. [CrossRef]

5. Wilenksy, U.; Rand, W. An Introduction to Agent-Based Modeling. Modeling Natural, Social and Engineered Complex Systems in NetLogo; MIT Press: Cambridge, MA, USA, 2015.

6. Haas, A.; Grapin, S.E.; Wendel, D.; Llosa, L.; Lee, O. How fifth-grade English learners engage in systems thinking using computational models. Systems 2020, 8, 47. [CrossRef]

7. Pierson, A.E.; Brady, C.E. Expanding opportunities for systems thinking, conceptual learning, and participation through embodied and computational modeling. Systems 2020, 8, 48. [CrossRef] 
8. Cottone, A.M.; Yoon, S.A.; Coulter, B.; Shim, J.; Carman, S. Building system capacity with a modeling-Based inquiry program for elementary students: A case study. Systems 2021, 9, 9. [CrossRef]

9. Marei, A.; Yoon, S.A.; Yoo, J.-U.; Richman, T.; Noushad, N.; Miller, K.; Shim, J. Designing feedback systems: Examining a feedback approach to facilitation in an online asynchronous professional development course for high school science teachers. Systems 2021, 9, 10. [CrossRef] 